\title{
Estimation of genetic diversity in sorghum genotypes of Pakistan
}

\author{
Aamer Mumtaz, Dilbar Hussain, Muhammad Saeed, Muhammad Arshad and Muhammad Irfan \\ Yousaf \\ Sorghum Breeding Section, Maize and Millet Research Institute, Yusafwala, Sahiwal, Pakistan.
}

Revised: 13 October 2017; Accepted: 21 December 2017

\begin{abstract}
Livestock and poultry production is increasing steadily in Pakistan but the production of poultry feed, cattle feed and fodder is not increasing at the same rate, and Pakistan is now facing a shortage of quality fodder and poultry feed. Sorghum is a good alternative to meet the growing fodder and poultry feed requirements. The major barrier in enhancing sorghum production is the lack of sufficient information on the genetic diversity of sorghum genotypes in Pakistan. In this study 30 sorghum genotypes from the gene pool maintained by the Maize and Millet Research Institute, Yusafwala, Sahiwal, Pakistan were sown in 2015 in a randomised complete block design. Morphological data such as days to $50 \%$ anthesis, plant height, flag leaf area, brix percentage, panicle length, 1000 grain weight and grain yield were recorded. Data were evaluated for statistical significance using principal component analysis (PCA) and cluster analysis. A highly significant variation was observed among the genotypes. The percentage coefficient of variation in all traits was less than $10 \%$, which showed that uncontrolled variation was highly unlikely. A close correlation was seen between flag leaf area and grain yield, days to $50 \%$ anthesis and 1000 grain weight, and between panicle length and brix value. Flag leaf area, grain yield and 1000 grain weight indicated the least contribution to the total genetic diversity. The contribution of PC1, PC2 and PC3 was $64.5 \%$ of total variation. According to PCA and cluster analysis genotype YS-9 was important for the character days to $50 \%$ anthesis; genotype YS-22 for grain yield and flag leaf area; genotype YS-27 for plant height; genotype YS-10 and genotype YS-7 for panicle length; and genotype YS-12 for brix value.
\end{abstract}

Keywords: Biplot, cluster analysis, genetic diversity, PCA, Tukey.

\section{INTRODUCTION}

Milk and meat production as well as poultry and egg production can be increased with good quality fodder and feed (FAO, 2017). Livestock and poultry production is increasing steadily in Pakistan: in 2015, livestock production increased by $3.63 \%$ and poultry production by $7.6 \%$. But the land area used to grow fodder crops has decreased due to the unavailability of quality seeds. As a result, Pakistan is facing a shortage of quality cattle fodder and poultry feed (Govt. of Pakistan, 2016).

The total area used to grow fodder in Pakistan is 2.03 million hectares and the annual production was 4.03 million metric tons in 2015 - 2016. Sorghum [Sorghum bicolor (L.) Moench] occupy 0.195 million hectares with a total production of 0.104 million metric tons in 2015 - 2016, accounting for $12.16 \%$ of the total fodder crop production in Pakistan. These figures make sorghum the second largest fodder crop after barseem, which accounts for $43.54 \%$ of the total (Pakistan Bureau of Statistics, 2016). The recommended proportion of sorghum in poultry feed is $15-20 \%$ (PARC, 2016). Sorghum is currently considered a good option for meeting the national requirements for high quality cattle and poultry feed in Pakistan.

Further, it is an important coarse grain crop in rainfed and arid zones. In Pakistan, sorghum is important

*Corresponding author (aamer3002@gmail.com; (iD https://orcid.org/0000-0001-5621-1745) 
as a grain crop as well as a summer fodder crop (Bibi et al., 2010). It is the fifth most important cereal crop worldwide after wheat, rice, maize and barley (Ritter et al., 2007; Motlhaodi et al., 2014). It is not only a source of fodder for livestock, but its grains are also used in poultry feed as the best substitute for maize. Sorghum is a good source of carbohydrates and protein (Selle, 2011). The crop is thus increasingly valued in view of the expanding poultry industry. It is also gaining importance as a source of starch for textile industries, and is used in gum manufacture (FAO, 2016).

Genetic diversity is a gift of nature for the selection and development of crop varieties. Among the many causes of genetic diversity, the most important are natural mutation, geographical separation and genetic barriers (Zongo et al., 1993; Appa et al., 1996). Sorghum in Pakistan is not a native crop. It has been introduced from different African countries almost five decades ago and shows a considerable diversity. Although it is widely accepted that the knowledge on sorghum crop diversity is needed for genetic improvement, unfortunately there is little information available in Pakistan. Jain and Patel (2016) performed principal component analysis (PCA) for fodder yield and its components in sorghum accessions in India. It was observed that the first three principal components (PC) scored $70.89 \%$ variation. It was reported that the total variation was mainly due to variation in the fodder yield and their contributing traits i.e. stem girth, dry fodder yield, green fodder yield, days to $50 \%$ anthesis, leaf length, leaf width and number of leaves/plant. The 28 genotypes were grouped into four clusters with the help of cluster analysis on the basis of average linkage, and it was found that the varieties of first and second clusters were superior in terms of green and dry fodder yield, the third cluster for early maturity and the fourth for brix percent. Sinha and Kumaravadivel (2016) estimated the genetic diversity in sorghum genotypes in India. With the help of PCA, it was revealed that the stem girth, leaf breadth and panicle width contributed maximum towards divergence. Fourty accessions were grouped under 6 clusters. Cluster I contained the maximum number of accessions and cluster VI contained the minimum by using hierarchical cluster analysis. The highest mean value was observed for 1000 seed weight and grain yield in cluster III. For yield and yield related components, it was concluded that the selection of parents must be based on the wider inter-cluster distance and superior mean performance. In the present study, the genetic diversity of local sorghum genotypes was determined using morphological traits to provide information for future breeding programmes to develop better varieties and hybrids.

\section{METHODOLOGY}

Thirty sorghum accessions, selected from material imported from the International Crop Research Institute for Semi-Arid Tropics (ICRISAT), India were planted at the Maize and Millet Research Institute, Yusafwala, Sahiwal, Pakistan in 2015 in a randomised complete block design with three replicates. The size of each plot was $5 \times 3 \mathrm{~m}$. All agronomic practices, i.e., irrigation, fertiliser application, pesticide application, hoeing and thinning, etc. were done at appropriate times. Five plants were selected randomly from each entry for data collection.

Data were collected for the following traits: leaves per plant, days to $50 \%$ anthesis, plant height, flag leaf area, brix percentage, panicle length, 1000 grain weight and grain yield. The statistical significance of differences among accessions was determined according to Steel et al. (1998) using Statistix v. 8.1 software. PCA was used to correlate the standardised data of morphological traits recommended by Sneath and Sokal (1973) using XLSTAT software. The determination of genetic similarity was done using hierarchical cluster analysis (Sneath \& Sokal, 1973) using SPSS software.

\section{RESULTS AND DISCUSSION}

Statistical analysis detected highly significant variations among genotypes. Replication of the comparisons was not effective because of non-significant variations among replication attempts (Table 1). Descriptive statistics of morphological traits of thirty sorghum accessions are summarised in Table 2. The percentage coefficients of variation $(\mathrm{CV} \%)$ in all traits were less than 10 , which indicates that uncontrolled variations were highly unlikely. The largest ranges in values were seen for grain yield (2561.6 - 5190.2 $\left.\mathrm{kgha}^{-1}\right)$ and flag leaf area (135.14 $-315.31 \mathrm{~cm})$. The results of Tukey pairwise comparisons are shown in the Appendix.

\section{Principal component analysis}

PCA is interpreted based on the correlations among variables: the further the number from zero in either direction, the greater the positive or negative correlation. Consideration of the magnitude of these numbers is a subjective decision and is needed to determine the level of correlation at which a given value is considered as important (Ringner, 2008). In this analysis three PCs yielded values greater than 1: PC1 26.85\%, PC2 21.03\%, and PC3 $16.48 \%$ (Table 3). Together they contributed to 
Table 1: Analysis of variance of sorghum accessions for morphological traits

\begin{tabular}{lccccccrr}
\hline Source & DF & Brix $\%$ & D 50 \% & FLA & GW & GY & HL & PH \\
\hline Rep & 2 & 4.01 & $176.478^{\text {NS }}$ & $1227.4^{\text {NS }}$ & $19.3368^{\text {NS }}$ & $592333^{\text {NS }}$ & $17.2794^{\text {NS }}$ & $838.8^{\text {NS }}$ \\
Gen & 29 & 45.40 & $21.925^{* *}$ & $26213.6^{* *}$ & $88.7054^{* *}$ & $1366555^{* *}$ & $80.90^{* *}$ & $16174.1^{* *}$ \\
Error & 58 & 0.0681 & 3.110 & 12.8 & 0.4102 & 10982 & 5.7778 & 9.5 \\
Total & 89 & & & & & & & \\
\hline
\end{tabular}

Rep - replication; Gen - genotype; D $50 \%$ - days to $50 \%$ anthesis; FLA - flag leaf area; GW - 1000 grain weight; GY - grain yield; $\mathrm{HL}$ - panicle length; PH - plant height; ${ }^{* *}$ - significant; ${ }^{\mathrm{NS}}$ - non-significant

Table 2: Descriptive statistics of sorghum accessions for morphological traits

\begin{tabular}{lrrrrrr}
\hline Variable & Mean & SD & Minimum & Maximum & Range & CV \\
\hline Brix \% & 10.61 & 3.89 & 3.40 & 18.12 & 14.72 & 2.46 \\
D 50 \% & 77.60 & 2.72 & 72.00 & 82.00 & 10.00 & 2.27 \\
FLA $(\mathrm{cm})$ & 263.65 & 93.48 & 135.14 & 450.45 & 315.31 & 1.36 \\
GW $(\mathrm{g})$ & 26.59 & 5.44 & 18.02 & 39.77 & 21.75 & 2.41 \\
GY $\left(\mathrm{kgha}^{-1}\right)$ & 4149.20 & 674.92 & 2561.60 & 5190.20 & 2628.60 & 2.53 \\
HL $(\mathrm{cm})$ & 26.11 & 5.19 & 17.02 & 38.04 & 21.02 & 9.21 \\
PH $(\mathrm{cm})$ & 239.84 & 73.43 & 132.13 & 380.38 & 248.25 & 1.29 \\
\hline
\end{tabular}

D $50 \%$ - days to $50 \%$ anthesis; FLA - flag leaf area; GW - 1000 grain weight; GY - grain yield; HL - panicle length; $\mathrm{PH}$ - plant height

Table 3: Principal component analysis of sorghum accessions

\begin{tabular}{lrrrrrrr}
\hline & F1 & F2 & F3 & F4 & F5 & F6 & F7 \\
\hline Eigenvalue & 1.879 & 1.472 & 1.153 & 0.872 & 0.627 & 0.570 & 0.427 \\
Variability \% & 26.847 & 21.029 & 16.475 & 12.455 & 8.953 & 8.140 & 6.100 \\
Cumulative \% & 26.847 & 47.876 & 64.352 & 76.807 & 85.760 & 93.900 & 100.000 \\
\hline
\end{tabular}

Table 4: Squared cosines of the variables for morphological traits

\begin{tabular}{llllll}
\hline & F1 & F2 & F3 & F4 & F5 \\
\hline Brix \% & 0.021 & $\mathbf{0 . 5 6 1}$ & 0.034 & 0.238 & 0.001 \\
D 50 \% & $\mathbf{0 . 6 9 7}$ & 0.004 & 0.000 & 0.007 & 0.000 \\
FLA $(\mathrm{cm})$ & 0.247 & 0.009 & $\mathbf{0 . 4 6 9}$ & 0.010 & 0.136 \\
GW $(\mathrm{g})$ & $\mathbf{0 . 5 7 4}$ & 0.031 & 0.004 & 0.017 & 0.290 \\
GY $\left(\mathrm{kgha}^{-1}\right)$ & 0.114 & $\mathbf{0 . 5 7 6}$ & 0.015 & 0.010 & 0.135 \\
HL $(\mathrm{cm})$ & 0.058 & 0.271 & 0.122 & $\mathbf{0 . 4 7 3}$ & 0.040 \\
PH $(\mathrm{cm})$ & 0.169 & 0.021 & $\mathbf{0 . 5 1 0}$ & 0.116 & 0.024 \\
\hline
\end{tabular}

D $50 \%$ - days to $50 \%$ anthesis; FLA - flag leaf area; GW - 1000 grain weight; GY - grain yield; HL - panicle length; $\mathrm{PH}$ - plant height

The bold values are significant 
$64.35 \%$ of the total variation, whereas other correlations accounted for the remaining $35.65 \%$.

The first component correlated strongly with plant height (positive factor loading) and brix value (negative factor loading). The second component showed considerable positive loading for days to $50 \%$ anthesis and panicle length. The third component showed strong correlations with flag leaf area (positive factor loading) and grain yield (negative factor loading) (Tables 4 and 5).

The percentage variations are shown in the scree plot (Figure 1) generated with eigenvalues on the y-axis and $\mathrm{PC}$ analysis results on the $\mathrm{x}$-axis. The greatest variation was due to $\mathrm{PC} 1, \mathrm{PC} 2$ and $\mathrm{PC} 3$ whereas the other components contributed to much less variation. In addition, PC1 accounted for the largest contribution to total genetic diversity.

\section{Biplot analysis}

Biplot analysis aids in selection processes and targeting selection objectives by visualising similarities and correlations between traits. Figure 2 clearly shows close associations between plant height, flag leaf area and grain yield. Flag leaf area and grain yield were strongly correlated (arrows of the same length), as were days to $50 \%$ anthesis and 1000 grain weight, and panicle length and brix value. Flag leaf area and grain yield contributed less to total genetic diversity (very short arrows), as did 1000 grain weight compared to other traits. Biplot analysis was also used by Jain and Patel (2016) to estimate the genetic diversity in sorghum, where a large genetic diversity was observed because the genotypes remained scattered in all four quadrants. The positive values on the vertical axis are linked with plant height, while flag leaf area and grain yield are linked with positive values on both the vertical and horizontal axes. Days to

Table 5: Factor loading of morphological traits

\begin{tabular}{lccccc}
\hline & F1 & F2 & F3 & F4 & F5 \\
\hline Brix \% & 0.144 & 0.749 & -0.186 & -0.488 & 0.032 \\
D 50 \% & 0.835 & 0.063 & -0.007 & -0.085 & -0.020 \\
FLA $(\mathrm{cm})$ & 0.497 & 0.093 & -0.685 & 0.100 & 0.369 \\
GW $(\mathrm{g})$ & -0.757 & 0.177 & 0.061 & -0.132 & 0.538 \\
GY $\left(\mathrm{kgha}^{-1}\right)$ & -0.338 & 0.759 & -0.121 & 0.099 & -0.367 \\
HL $(\mathrm{cm})$ & 0.240 & 0.521 & 0.350 & 0.688 & 0.200 \\
PH $(\mathrm{cm})$ & 0.411 & 0.143 & 0.714 & -0.340 & 0.156 \\
\hline
\end{tabular}

D $50 \%$ - days to $50 \%$ anthesis; FLA - flag leaf area; GW - 1000 grain weight; GY - grain yield; HL panicle length; $\mathrm{PH}$ - plant height

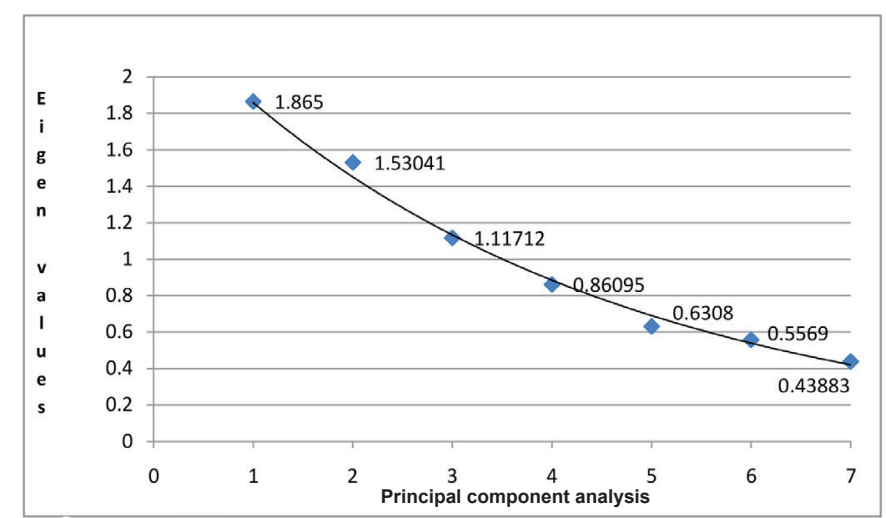

Figure 1: Scree plot resulting from PCA of sorghum genotypes in Pakistan 


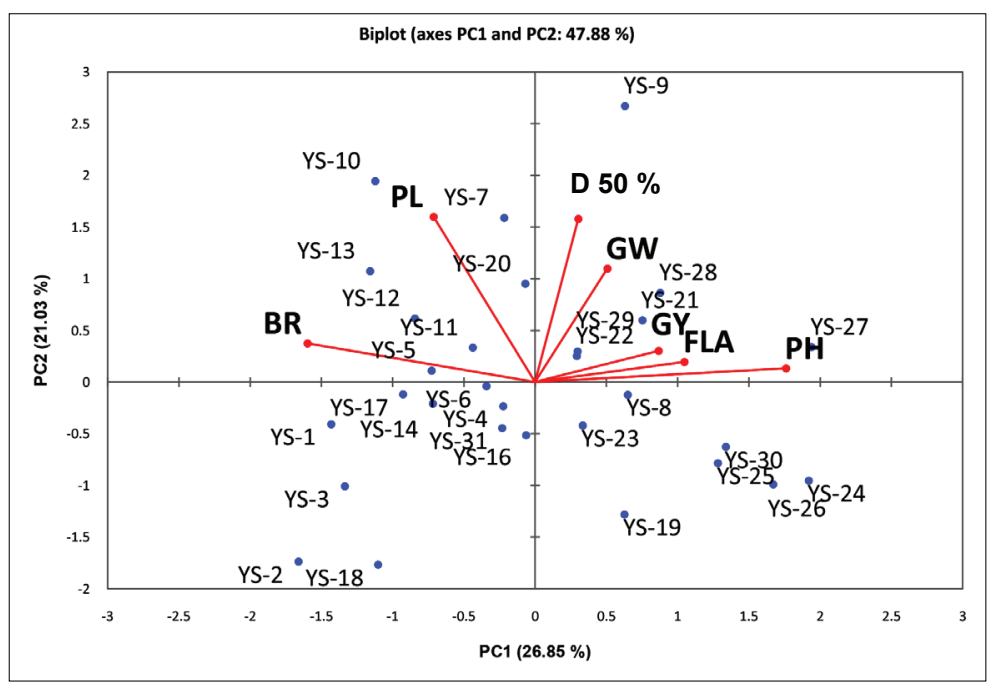

Figure 2: Biplot of sorghum genotypes

BR - brix; PL - panicle length; D $50 \%$ - days to $50 \%$ anthesis; GW - grain weight; GY - grain yield; FLA - flag leaf area; PH - plant height

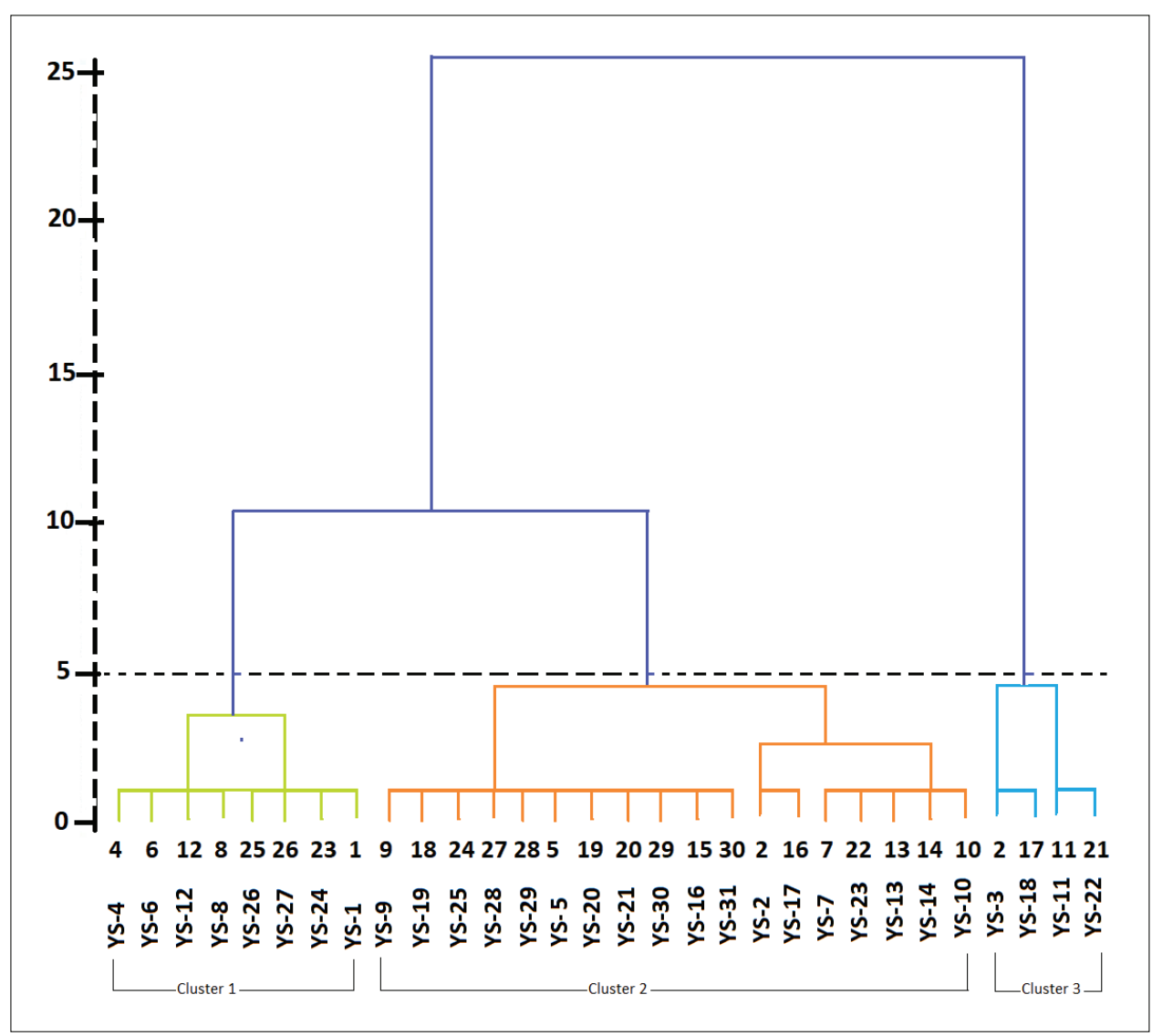

Figure 3: Dendrogram resulting from cluster analysis of sorghum genotypes 
Table 6: Contribution of genotypes to factors (\%) for variation

\begin{tabular}{|c|c|c|c|c|c|}
\hline & F1 & F2 & F3 & F4 & F5 \\
\hline YS-1 & 6.833 & 0.549 & 7.035 & 1.199 & 6.983 \\
\hline YS-2 & 9.188 & 10.046 & 0.582 & 2.794 & 0.310 \\
\hline YS-3 & 5.947 & 3.386 & 1.779 & 13.202 & 0.345 \\
\hline YS-4 & 0.167 & 0.180 & 17.281 & 3.591 & 1.170 \\
\hline YS-5 & 1.760 & 0.041 & 0.557 & 16.526 & 3.796 \\
\hline YS-6 & 0.390 & 0.005 & 5.662 & 2.419 & 6.050 \\
\hline YS-7 & 0.156 & 8.427 & 0.163 & 12.794 & 0.122 \\
\hline YS-8 & 1.409 & 0.050 & 3.364 & 0.150 & 0.337 \\
\hline YS-9 & 1.321 & 23.801 & 1.025 & 7.852 & 2.180 \\
\hline YS-10 & 4.198 & 12.606 & 0.242 & 0.170 & 2.890 \\
\hline YS-11 & 0.638 & 0.373 & 3.403 & 2.173 & 0.066 \\
\hline YS-12 & 2.379 & 1.261 & 11.797 & 6.323 & 8.870 \\
\hline YS-13 & 4.474 & 3.848 & 1.056 & 4.798 & 3.790 \\
\hline YS-14 & 1.715 & 0.143 & 0.000 & 0.037 & 12.694 \\
\hline YS-16 & 0.014 & 0.879 & 2.255 & 0.041 & 1.069 \\
\hline YS-17 & 2.861 & 0.047 & 0.207 & 4.461 & 1.824 \\
\hline YS-18 & 4.052 & 10.395 & 3.828 & 0.233 & 7.573 \\
\hline YS-19 & 1.309 & 5.477 & 5.550 & 0.414 & 5.636 \\
\hline YS-20 & 0.016 & 3.018 & 0.806 & 0.959 & 3.551 \\
\hline YS-21 & 1.887 & 1.192 & 0.225 & 1.388 & 3.474 \\
\hline YS-22 & 0.286 & 0.213 & 5.880 & 0.127 & 1.723 \\
\hline YS-23 & 0.370 & 0.589 & 4.552 & 0.195 & 1.551 \\
\hline YS-24 & 12.285 & 3.014 & 1.781 & 1.122 & 0.375 \\
\hline YS-25 & 5.485 & 2.042 & 5.794 & 1.746 & 13.445 \\
\hline YS-26 & 9.297 & 3.268 & 6.264 & 0.248 & 4.914 \\
\hline YS-27 & 12.542 & 0.383 & 2.019 & 0.374 & 0.730 \\
\hline YS-28 & 2.569 & 2.498 & 1.274 & 1.232 & 0.150 \\
\hline YS-29 & 0.294 & 0.296 & 0.011 & 12.919 & 1.599 \\
\hline YS-30 & 5.977 & 1.310 & 2.873 & 0.157 & 0.553 \\
\hline YS-31 & 0.179 & 0.660 & 2.735 & 0.356 & 2.230 \\
\hline
\end{tabular}

$50 \%$ anthesis, 1000 grain weight and panicle length are linked with positive values on the horizontal axis, whereas brix value shows negative vertical axis values. This information is helpful in clarifying trait correlations among genotypes. Performance of genotypes for any trait could be determined with the arrow direction and position of the genotype (Aslam et al., 2014). The genotypes which showed better performance for different traits are; genotype YS-9 for days to $50 \%$ anthesis, genotype YS-28 for 1000 grain weight, and genotype YS-21 and YS-29 for grain yield. Genotype YS-22 showed better performance for grain yield and flag leaf area. For plant height, genotypes YS-27 and YS-8 showed better performance. For panicle length, better performance was observed for genotypes YS-10, YS-7 and YS-20. For brix value, the best performing were genotypes YS- 5, YS-6, YS-1, YS-4, YS-11, YS-12, YS-14 and YS-17. Genotype YS-13 showed better performance with both panicle length and brix value (location midway between the two arrows). The genotypes YS-2, YS-3, YS-16, YS-18, YS-19, YS-23, YS-24, YS-25, YS-26 and YS-30 showed no significant improvement for any trait (location at the axes with no trait arrows) (Figure 3). The largest contributions to genetic diversity were from the genotypes YS-27, YS-24 and YS-26 in PC1, YS-9, YS-10 and YS-18 in PC2, and YS-4, YS-12 and YS-1 in PC3 (Table 6).

The results show that PC analysis can be helpful in evaluating crop production data. Makanda et al. (2011) and Sinha and Kumaravadivel (2016) also found significant differences among different morphological traits in sorghum.

According to PC analysis, selective breeding would be favoured with YS-9 for days to $50 \%$ anthesis, YS-28 
for 1000 grain weight, YS-29 for grain yield, YS-22 for grain yield and flag leaf area, YS-27 and YS- 8 for plant height, YS-10 and YS-7 for panicle length, and YS-1, YS-4, YS-5, YS-6 and YS-12 for brix value. Although genotypes YS-1, YS-4 and YS-12 yielded moderate correlations, they made the largest contributions to total genetic diversity in PC3. Similarly, large contributions to the total genetic diversity makes YS-9 the best genotype for days to $50 \%$ anthesis, whereas YS-27 and YS-8 are optimum choices to select for plant height, and YS-10 and YS-7 for panicle length.

Shergo et al. (2013) found maximum contribution of the first two PCs in sorghum genotypes. Kisua et al. (2014) and Sinha and Kumaravadivel (2016) observed maximum contribution of the first four PCs in sorghum genotypes, and Sinha and Kumaravadivel (2016) observed maximum contribution of the first three PCs to total genetic diversity in sorghum genotypes. The present study is similar to data from Sinha and Kumaravadivel (2016) in contribution of PCs to total genetic diversity because they found maximum contribution of stem girth and leaf breadth towards divergence. The previous study also evaluated the contribution of different morphological traits to total genetic diversity similar to the present study. The results of this study also agree with Felix et al. (2015), where widespread varieties were observed in the biplot which represent the large diversity in sorghum germplasm.

\section{Cluster analysis}

Cluster analysis is a data exploration (mining) tool that can divide a multivariate dataset into natural clusters (groups). This approach grouped the 30 sorghum genotypes into three clusters of 8,18 and 4 genotypes (Figure 3, Table 8). The genotypes in the first cluster had high mean values for grain weight and grain yield, while those in the second cluster had high mean values for days to $50 \%$ anthesis, plant height, flag leaf area and panicle length. Members of the third cluster had high brix percentage values (Table 7).

These results are depicted in the dendrogram, which shows two main groups, the first of which is further divided into two subgroups. According to these groupings, selection of genotypes from cluster 2 should be selected to favour days to $50 \%$ anthesis, plant height, flag leaf area and panicle length. The brix value contributes for cluster 3 while grain weight and grain yield contribute for cluster 1 .

Cluster 2 contained the largest number of genotypes, followed by cluster 1 and cluster 3 , which contained fewer genotypes. Shergo et al. (2013) observed five clusters in their study. Kisua et al. (2014) observed three clusters and Sinha and Kumaravadivel (2016) observed four clusters in sorghum. The results of this study agree with Kisua et al. (2014), as they observed that the accessions which plot in different parts of the biplot would be the most informative for distinguishing accessions with narrow and wide diversity. Also, the selection of traits was similar to those in this study. The results to this study were somewhat different with respect to Shergo et al. (2013), as they observed comparatively more genetic diversity. The main reason for this is that they performed cluster analysis on morphological as well as quality traits. The genetic diversity observed by Sinha and Kumaravadivel (2016) was also comparatively higher because they evaluated some complicated traits like leaf length, leaf breadth and number of leaves.

The two statistical methods predicted somewhat different results for 1000 grain weight. According to PCA YS-18 is important for 1000 grain weight, whereas according to cluster analysis YS-4, YS-6, YS-12, YS-8, YS-26, YS-27, YS-24 and YS-1 are important for the same trait.

For most traits there is consensus based on PCA and cluster analysis. For efficient breeding, variety and hybrid development, preference should be given to: genotype YS-9 for short duration plants, genotype Y-22 for high grain yield, genotype YS-27 for medium height plants, genotypes YS-19 and YS-7 for long panicle, and for sweeter stalks preference should be given to genotype YS-12. Days to $50 \%$ anthesis, 1000 grain weight and panicle length are positively correlated highlighting the fact that care is needed for joint selection of these traits. If selection is done considering these genotypes and traits in combination, it will surely lead to a high yielding, medium height and high sweet stalk variety.

Table 7: Cluster analysis of sorghum accessions for morphological traits

\begin{tabular}{llll}
\hline Variable & Cluster 1 & Cluster 2 & Cluster 3 \\
\hline Brix \% & 9.61 & 10.33 & 10.61 \\
D 50 \% & 77 & 78.36 & 77 \\
FLA & 201.98 & 323.67 & 247.25 \\
GW & 29.01 & 25.16 & 25.70 \\
GY & 4929.80 & 4269.08 & 2903.40 \\
HL & 22.96 & 26.57 & 24.52 \\
PH & 252.88 & 274.82 & 206.46 \\
\hline
\end{tabular}

$\mathrm{D}=$ days to $50 \%$ anthesis; $\mathrm{PH}=$ plant height; $\mathrm{FLA}=$ flag leaf area; $\mathrm{HL}=$ panicle length; $\mathrm{GW}=$ grain weight $\mathrm{GY}=$ grain yield 
Table 8: Summarisation of sorghum genotypes for cluster analysis

\begin{tabular}{ccl}
\hline Cluster & $\begin{array}{c}\text { No. of } \\
\text { genotypes }\end{array}$ & Name of genotypes \\
\hline 1 & 8 & YS-1, YS-4, YS-6, YS-8, YS-12, YS-24, YS-26, YS-27 \\
2 & 18 & $\begin{array}{l}\text { YS-2, YS-5, YS-7, YS-9, YS-10, YS-13, YS-14, YS-16, YS-17, YS-19, } \\
\text { YS-20, YS-21, YS-23, YS-25, YS-28, YS-29, YS-30, YS-31 } \\
3\end{array}$ \\
& 4 & YS-3, YS-11, YS-18, YS-22 \\
\hline
\end{tabular}

\section{CONCLUSION}

Significant variations were found among genotypes, and both PCA and cluster analysis can be helpful in identifying genotypes which merit further evaluation. Flag leaf area correlated closely with grain yield, days to $50 \%$ anthesis and 1000 grain weight, and panicle length correlated closely with brix value. Flag leaf area, grain yield and 1000 grain weight contributed least to total genetic diversity. The results of the two statistical analyses for 1000 grain weight were inconclusive: PCA suggested that YS-18 is important whereas cluster analysis identified YS-4, YS-6, YS-12, YS-8, YS-26, YS-27, YS-24 and YS-1 as important for 1000 grain weight. But for most traits, there is consensus between PCA and cluster analysis; selective breeding will be favoured with genotype YS-9 for short duration plants, genotype YS-22 for high grain yield, YS-27 for medium height plants, genotype YS-10 and YS-7 for long panicles, and genotype YS-12 for sweeter stalks for best variety and hybrid development.

\section{Acknowledgement}

The authors are grateful to the field staff of the Maize and Millet Research Institute, Yusafwala, Pakistan for their efforts. The authors thank Dr Abid Mehmood, Director General of Agricultural Research (Punjab) and the Government of Punjab for their support. The authors also thank K. Shahsok (AuthorAID in the Eastern Mediterranean) for improving the use of English in the manuscript, and Dr Wasim Akbar for his moral support.

\section{REFERENCES}

Appa R.S., Rao P., Mengesha M.H. \& Reddy V.G. (1996). Morphological diversity in sorghum germplasm from India. Genetic Resource Crop Evolution 43(6): 559 - 567. DOI: https://doi.org/10.1007/BF00138832
Aslam M., Zeeshan M., Maqbool M.A. \& Farid B. (2014). Assessment of drought tolerance in maize (Zea may L.) genotypes at early growth stages by using principle component and biplot analysis. The Experiment 29(1): 1943 - 1951.

Bibi A., Sadaqat H.A., Akram H.M. \& Mohammed M.I. (2010). Physiological markers for screening sorghum (Sorghum bicolor) germplasm under water stress condition. International Journal of Agriculture and Biology 12(3): 451-455.

Felix K., Cheruiyot E., Mwendia C.M., Francis W.N. \& Kimani P. (2015). Genetic variation of biochemical characteristics of selected sorghum genotypes from East Africa. African Journal of Food Science 9(5): 314 - 321.

DOI: https://doi.org/10.5897/AJFS2014.1284

Food and Agriculture Organization (FAO) (2017). FAOSTAT 2017. Food and Agriculture Organization. United Nations, Rome, Italy. Available at http://www.fao.org/docrep/005/ y4252e/y4252e07.htm

Government of Pakistan (2016). Economic Survey of Pakistan. Finance Division, Economic Advisory Wing, Islamabad, Pakistan.

Jain S.K. \& Patel P.R. (2016). Principal component and cluster analysis in sorghum (Sorghum bicolor L. Moench). Forage Research 42(3): $90-95$.

Kisua J., Mwikamba J. \& Muigai A. (2014). Genetic diversity of sweet and grain sorghum populations using phenotypic markers. International Crop Research Institute for SemiArid Tropics 9: $34-46$.

DOI: https://doi.org/10.12692/ijb/6.9.34-46

Makanda I., Derera J., Tongoona P. \& Sibiya J. (2011). Genetic and GGE biplot analyses of sorghum germplasm for stem sugar traits in Southern Africa. African Journal of Agricultural Research 7(2): 212 - 223.

Motlhaodi T., Geleta M., Bryngelsson T., Fatih M., Chite S. \& Ortiz R. (2014). Genetic diversity in ex-situ conserved sorghum accessions of Botswana as estimated by: microsatellite markers. Australian Journal of Crop Sciences 8(1): $35-43$.

Pakistan Agriculture Research Council (PARC) (2016). Maize, Sorghum and Millets. Pakistan Agriculture Research Council, Islamabad, Pakistan.

Pakistan Bureau of Statistics (2016). Agriculture Statistics. 
Ministry of Finance, Islamabad, Pakistan.

Ringner M. (2008). What is principal component analysis?. Nature Biotechnology 26: $303-304$.

DOI: https://doi.org/10.1038/nbt0308-303

Ritter K.B., McIntyre C.L., Godwin I.D., Jordan D.R. \& Chapman S.C. (2007). An assessment of the genetic relationship between sweet and grain sorghums, within Sorghum bicolor ssp. bicolor (L.) Moench, using AFLP markers. Euphytica 157(1 - 2): 161 - 176. DOI: https://doi.org/10.1007/s10681-007-9408-4

Selle P.H. (2011). The protein quality of sorghum. $22^{\text {nd }}$ Annual Australian Poultry Science Symposium, Sydney, New South Wales, 14 - 16 February, The Poultry Research Foundation, University of Sydney, Australia.

Shergo A., Labuschagne M.T., Biljonand A.V. \& Shargie N.G. (2013). Assessment of genetic diversity in sorghum accessions using amplified fragment length polymorphism
(AFLP) analysis. African Journal of Biotechnology 12(11): $1178-1188$.

Sinha S. \& Kumaravadivel N. (2016). Understanding genetic diversity of Sorghum using quantitative traits. Scientifica 2016: Article ID 3075023.

DOI: https://doi.org/10.1155/2016/3075023

Sneath P.H.A. \& Sokal R.R. (1973). Numerical Taxonomy: The Principles and Practice of Numerical Classification. FreeMan WF and Co., San Francisco, USA.

Steel R.G.D., Torrie J.H. \& Dickey D.A. (1997). Principles and Procedures of Statistics. A Biometrical Approach, $3^{\text {rd }}$ edition. McGraw Hill Book Co., New York, USA.

Zongo D., Gouyon P.H. \& Sandmeier M. (1993). Genetic variability among sorghum accessions from the Sahelian agroecological region of Burkina Faso. Biodiversity and Conservation 2(6): $627-636$.

DOI: https://doi.org/10.1007/BF00051963 


\section{Appendix}

Tukey mean comparisons

\begin{tabular}{|c|c|c|c|c|c|c|c|}
\hline & Brix (\%) & D $50 \%$ & $\operatorname{FLA}\left(\mathrm{cm}^{2}\right)$ & GW (g) & $\mathrm{GY}(\mathrm{g})$ & $\mathrm{HL}(\mathrm{cm})$ & $\mathrm{PH}$ \\
\hline 1 & $17.417^{\text {в }}$ & $77.000^{\mathrm{DEF}}$ & $145.15^{\mathrm{R}}$ & $26.205^{\mathrm{IJ}}$ & $4670.7^{\mathrm{C}}$ & $22.023^{\mathrm{H}}$ & $132.13^{Q}$ \\
\hline 2 & $14.914^{\mathrm{CD}}$ & $72.000^{\mathrm{H}}$ & $158.56^{Q}$ & $24.027^{\mathrm{K}}$ & $3502.5^{\mathrm{L}}$ & $22.023^{\mathrm{H}}$ & $140.14^{\mathrm{P}}$ \\
\hline 3 & $13.616^{\mathrm{E}}$ & $74.000 \mathrm{GH}$ & $224.22^{\mathrm{L}}$ & $29.560^{\mathrm{FG}}$ & $2561.6^{\mathrm{N}}$ & $23.023^{\mathrm{FGH}}$ & $165.16^{\mathrm{NO}}$ \\
\hline 4 & $10.911 \mathrm{JK}$ & $75.0000^{\mathrm{FG}}$ & $448.45^{\mathrm{A}}$ & $34.633^{\mathrm{C}}$ & $5138.1 \mathrm{AB}$ & $23.023{ }^{\mathrm{FGH}}$ & $167.17^{\mathrm{N}}$ \\
\hline 5 & $15.215^{\mathrm{C}}$ & $82.000^{\mathrm{A}}$ & $160.16^{\mathrm{Q}}$ & 19.358 оP & $4203.2 \mathrm{EFG}$ & $22.523 \mathrm{GH}$ & $190.19^{\mathrm{M}}$ \\
\hline 6 & $8.106^{\circ}$ & $77.000^{\mathrm{DEF}}$ & $252.25^{\mathrm{K}}$ & 23.023 KLM & $5190.2^{\mathrm{A}}$ & $29.530^{\mathrm{CD}}$ & $165.16^{\mathrm{NO}}$ \\
\hline 7 & $11.113^{\mathrm{HJJ}}$ & $78.000 \mathrm{CDE}$ & $171.17^{\mathrm{P}}$ & $37.408^{\mathrm{B}}$ & $3891.9^{\mathrm{IJ}}$ & $34.037^{\text {В }}$ & $198.20^{\mathrm{L}}$ \\
\hline 8 & $9.510^{\mathrm{N}}$ & 77.000 DEF & $328.33^{\mathrm{F}}$ & $28.086^{\mathrm{H}}$ & $5004.0^{\text {в }}$ & $24.027 \mathrm{EFGH}$ & $270.27^{\mathrm{E}}$ \\
\hline 9 & $11.513^{\mathrm{FGH}}$ & $81.000^{\mathrm{AB}}$ & $254.25^{\mathrm{K}}$ & $39.768^{\mathrm{A}}$ & $4163.2^{\mathrm{FG}}$ & $36.037^{\mathrm{AB}}$ & $280.28^{\mathrm{D}}$ \\
\hline 10 & $14.517^{\mathrm{D}}$ & $81.000 \mathrm{AB}$ & $405.41^{\text {в }}$ & $27.907^{\mathrm{H}}$ & $3736.7^{\mathrm{JK}}$ & $38.037^{\mathrm{A}}$ & $225.23 \mathrm{HI}$ \\
\hline 11 & $11.914^{\mathrm{F}}$ & $78.000^{\mathrm{CDE}}$ & $396.40^{\mathrm{C}}$ & $28.649 \mathrm{GH}$ & $3269.3^{\mathrm{M}}$ & $28.027^{\mathrm{CD}}$ & $220.22^{\mathrm{I}}$ \\
\hline 12 & $18.116^{\mathrm{A}}$ & $80.000^{\mathrm{ABC}}$ & $196.20^{\mathrm{M}}$ & $27.917^{\mathrm{H}}$ & $5190.2^{\mathrm{A}}$ & $24.027 \mathrm{EFGH}$ & $207.21^{\mathrm{JK}}$ \\
\hline 13 & $13.715^{\mathrm{E}}$ & $80.000^{\mathrm{ABC}}$ & $304.30^{\mathrm{G}}$ & $20.460^{\mathrm{N}}$ & $3970.0 \mathrm{HI}$ & $36.037^{\mathrm{AB}}$ & $202.20 \mathrm{KL}$ \\
\hline 14 & $7.705^{\circ}$ & 77.000 DEF & $135.13^{\mathrm{s}}$ & $22.672^{\mathrm{M}}$ & $3891.9^{\text {IJ }}$ & $30.030^{\mathrm{C}}$ & $167.17^{\mathrm{N}}$ \\
\hline 15 & $7.907^{\circ}$ & $75.333 \mathrm{EFG}$ & $224.22^{\mathrm{L}}$ & 20.321 No & $4437.4^{\mathrm{D}}$ & $30.030^{\mathrm{C}}$ & $170.17^{\mathrm{N}}$ \\
\hline 16 & $13.616^{\mathrm{E}}$ & $76.000 \mathrm{EFG}$ & $179.38^{\circ}$ & $29.931 \mathrm{EF}$ & $3589.6^{\mathrm{KL}}$ & 26.027 DEFG & $160.16^{\circ}$ \\
\hline 17 & $10.209^{\mathrm{LM}}$ & $74.000 \mathrm{GH}$ & $384.38^{\mathrm{D}}$ & $18.017^{Q}$ & $2668.7^{\mathrm{N}}$ & $24.027^{\mathrm{EFGH}}$ & $210.21^{\mathrm{J}}$ \\
\hline 18 & $11.811^{\mathrm{FG}}$ & $74.000 \mathrm{GH}$ & $273.27^{\mathrm{J}}$ & $19.080^{\mathrm{P}}$ & $4203.2 \mathrm{EFG}$ & $23.023 \mathrm{FGH}$ & $300.30^{\mathrm{C}}$ \\
\hline 19 & $13.815^{\mathrm{E}}$ & $80.000^{\mathrm{ABC}}$ & $180.18^{\circ}$ & $26.835^{\mathrm{I}}$ & $4337.3^{\mathrm{DE}}$ & $29.030^{\mathrm{CD}}$ & $240.24^{\mathrm{G}}$ \\
\hline 20 & $5.603^{Q}$ & $81.000^{\mathrm{AB}}$ & $450.45^{\mathrm{A}}$ & $26.196^{\mathrm{IJ}}$ & $4323.3^{\mathrm{DEF}}$ & $27.027^{\mathrm{CDE}}$ & $250.25^{\mathrm{F}}$ \\
\hline 21 & $6.705^{\mathrm{P}}$ & $82.000^{\mathrm{A}}$ & $344.34^{\mathrm{E}}$ & $26.556^{\mathrm{I}}$ & $3114.1^{\mathrm{M}}$ & $23.023^{\mathrm{FGH}}$ & $230.23^{\mathrm{H}}$ \\
\hline 22 & $9.808^{\mathrm{MN}}$ & $78.000 \mathrm{CDE}$ & $280.28^{\mathrm{I}}$ & 23.593 KLM & $3882.9^{\mathrm{IJ}}$ & $23.023^{\mathrm{FGH}}$ & $230.23^{\mathrm{H}}$ \\
\hline 23 & $4.904^{\mathrm{R}}$ & $76.000 \mathrm{EFG}$ & $280.28^{\mathrm{I}}$ & $30.931^{\mathrm{E}}$ & $4670.7^{\mathrm{C}}$ & $17.017^{\mathrm{J}}$ & $350.35^{\text {B }}$ \\
\hline 24 & $11.411 \mathrm{GHI}$ & $78.000 \mathrm{CDE}$ & $384.38^{\mathrm{D}}$ & $22.845^{\mathrm{LM}}$ & $4087.1 \mathrm{GH}$ & 18.017 IJ & $345.34^{\text {B }}$ \\
\hline 25 & $4.007^{\mathrm{s}}$ & $75.333 \mathrm{EFG}$ & $294.29^{\mathrm{H}}$ & $28.229^{\mathrm{H}}$ & $4770.8^{\mathrm{C}}$ & $21.020^{\mathrm{HI}}$ & $380.38^{\mathrm{A}}$ \\
\hline 26 & $3.904^{\mathrm{s}}$ & $79.000^{\mathrm{BCD}}$ & $180.18^{\circ}$ & $33.033^{\mathrm{D}}$ & $4803.8^{\mathrm{C}}$ & $23.023^{\mathrm{FGH}}$ & $350.35^{\text {в }}$ \\
\hline 27 & $10.510^{\mathrm{KL}}$ & $78.000 \mathrm{CDE}$ & 275.48 IJ & $32.934^{\mathrm{D}}$ & $4283.3^{\mathrm{DEF}}$ & $29.027^{\mathrm{CD}}$ & $380.38^{\mathrm{A}}$ \\
\hline 28 & $11.411 \mathrm{GHI}$ & $81.000^{\mathrm{AB}}$ & $228.03^{\mathrm{L}}$ & $20.020^{\mathrm{NOP}}$ & $4203.2 \mathrm{EFG}$ & $26.527^{\mathrm{CDEF}}$ & $345.34^{\mathrm{B}}$ \\
\hline 29 & $3.404^{\mathrm{T}}$ & $78.000 \mathrm{CDE}$ & $190.19^{\mathrm{N}}$ & $23.864 \mathrm{KL}$ & $4281.3^{\mathrm{DEF}}$ & $22.023 \mathrm{H}$ & $250.25^{\mathrm{F}}$ \\
\hline 30 & $11.010^{\mathrm{IJ}}$ & $74.000 \mathrm{GH}$ & $180.18^{\circ}$ & $25.507^{\mathrm{J}}$ & $4437.4^{\mathrm{D}}$ & $29.027^{C D}$ & $270.27^{\mathrm{E}}$ \\
\hline
\end{tabular}

